\title{
Human Bone Marrow Derived Mesenchymal Stem Cells Regulate Leukocyte-Endothelial Interactions and Activation of Transcription Factor NF-Kappa B
}

Phillip A. Letourneau ${ }^{1,2}$, Tyler D. Menge ${ }^{1}$, Kathryn A. Wataha1, Charles E. Wade ${ }^{1,2}$, Charles S.Cox Jr ${ }^{3}$, John B. Holcomb ${ }^{1,2}$ and Shibani Pati ${ }^{1,2 *}$

${ }^{1}$ Center for Translational Injury Research, Texas Medical School at Houston, Houston, TX, USA

${ }^{2}$ Department of Surgery, Texas Medical School at Houston, Houston, TX, USA

${ }^{3}$ Department of Pediatric Surgery, Texas Medical School at Houston, Houston, TX, USA

\begin{abstract}
Bone marrow derived mesenchymal stem cells (MSCs) have been shown to demonstrate benefit in multiple disease models characterized by inflammation such as sepsis and acute lung injury. Mechanistically we hypothesized that MSCs exhibit these properties through inhibition of leukocyte activation and modulation of leukocyte-endothelial interactions; key interlinked processes involved in the deleterious effects of injury and inflammation. In this paper we found that MSCs co-cultured with a monocytoid line, U937, inhibit U937 binding to pulmonary endothelial cells (PECs) stimulated with the inflammatory cytokine TNFa. Furthermore, we show that these effects on functional adhesion are not due to changes in inflammatory adhesion molecule expression on U937s. No changes were found in CD62L, CD29, CD11b and CD18 expression on U937s co-cultured with MSCs. To determine if the effects of MSCs on leukocyte-endothelial interactions are due to the effects of MSCs on leukocyte activation, we investigated whether MSCs affect functional activation of the transcription factor NF-Kappa B. We found that MSCs significantly inhibit transcriptional activation of NF-kappa B in U937s. We also found that MSCs inhibit DNA binding of NF-kappa B subunits $p 50$ and p65 to putative NF-kappa B DNA binding sites. Concomitant with a decrease in NF-kappa B activation was a significant increase in IL-10, an anti-inflammatory cytokine known to inhibit activation of NF-kappa B. Taken together, these findings show that MSCs have potent effects on leukocyte-endothelial interactions which may be due to the direct effects of MSCs on IL-10 and NF-kB. These findings suggest a potential therapeutic role for MSCs in diseases characterized by inflammation such as acute lung injury or multi-organ failure induced by traumatic injury.
\end{abstract}

Keywords: Acute lung injury; Progenitor cells; Inflammation

Abbreviations: MSCs: Mesenchymal stem cells; PECs: pulmonary endothelial cells; TBI: traumatic brain injury; ALI: Acute Lung Injury; ARDS; Acute Respiratory Distress Syndrome; FBS: Fetal bovine serum; PBS: phosphate buffered solution; PMA: phorbol myristate acetate

\section{Introduction}

Human mesenchymal stem cells (MSCs) are pluripotent stromal cells that have demonstrated benefits when infused in multiple preclinical models of inflammation and injury, such as myocardial infarction, stroke, traumatic brain injury and lung injury [1-5]. Many of these studies have shown potent systemic and local effects of MSCs. Our past work has shown that MSCs have potent stabilizing effects on the vascular endothelium when administered intravenously after traumatic brain injury (TBI) [5]. In these studies we found that MSCs inhibit blood brain barrier permeability when administered after TBI, which appears to be due to the presence of soluble factor(s) produced by MSC administration. In addition to these stabilizing effects on the vascular endothelium, a number of groups have shown that MSCs have potent anti-inflammatory effects in models of disease characterized by high levels of inflammation such as Acute Lung Injury and Acute Respiratory Distress Syndrome (ALI and ARDS) [6-8]. Utilizing a mouse model of sepsis and ALI, Nemeth et al. have shown that MSCs improved survival through modulation of the innate immune system, specifically by modulating the release of PGE2 from lung macrophages leading to increased production of the anti-inflammatory cytokine IL-10. [7,9]. MSCs have also been shown to modulate immunological responses via T-cell suppression [10-12]. To date MSCs have been investigated as a new therapeutic strategy for $\mathrm{T}$ cell-mediated diseases such as graft-versus-host disease (GVHD), Crohn's disease, and the prevention of organ transplantation rejection [13]. In all of these disease contexts, limited numbers of MSCs have been observed to migrate to injured sites after systemic administration, but primarily most of the cells administered intravenously become lodged through a first-pass effect in the lung, liver or spleen regardless of the disease model $[14,15]$. Tissue-specific engraftment is not required and this aspect of MSC therapy in disease suggests a systemic effect of MSCs possibly produced by soluble factors.

Considering these data demonstrating an anti-inflammatory therapeutic effect of MSCs, we sought to find out more about their putative mechanisms of action. We hypothesized that MSCs regulate leukocyte activation and interaction with vascular endothelium, two processes that are highly interlinked and are key mediators of tissue injury in a number of disease states. To investigate these mechanisms of action, we designed in vitro experiments to study the effects of MSCs on leukocyte-endothelial interactions and leukocyte activation.

*Corresponding author: Shibani Pati, MD, PhD, Assistant Professor for Translational Injury Research, Department of Surgery University of Texas School of Medicine, Houston 6431 Fannin St. MSB 5.212 Houston, TX 77030, Tel: 713500-5417; Fax: 713-512-7135; E-mail: Shibani.pati@uth.tmc.edu

Received July 06, 2011; Accepted July 23, 2011; Published July 25, 2011

Citation: Letourneau PA, Menge TD, Wataha KA, Wade CE, Cox CS Jr, et al. (2011) Human Bone Marrow Derived Mesenchymal Stem Cells Regulate Leukocyte-Endothelial Interactions and Activation of Transcription Factor NFKappa B. J Tissue Sci Eng S3:001. doi:10.4172/2157-7552.S3-001

Copyright: @ 2011 Letourneau PA, et al. This is an open-access article distributed under the terms of the Creative Commons Attribution License, which permits unrestricted use, distribution, and reproduction in any medium, provided the original author and source are credited. 
Citation: Letourneau PA, Menge TD, Wataha KA, Wade CE, Cox CS Jr, et al. (2011) Human Bone Marrow Derived Mesenchymal Stem Cells Regulate Leukocyte-Endothelial Interactions and Activation of Transcription Factor NF-Kappa B. J Tissue Sci Eng S3:001. doi:10.4172/2157-7552. S3-001

Page 2 of 7

Our findings do indeed suggest that MSCs inhibit inflammation and leukocyte-endothelial interactions through direct interactions with leukocytes.

\section{Methods}

Primary cells and cell lines: First passage human MSCs and pulmonary endothelial cells (PECs) were purchased from Lonza (Walkersville, MD). MSCs were cultured in MSC growth media (MSCGM, Lonza); PECs were maintained in EGM-2MV media from Lonza. MSCs were used at passage 3-7 for all experiments. U937, a monocytoid immortalized cell line, were obtained from ATCC (Bethesda, MD) and passaged in RPMI 1640 with 10\% fetal bovine serum. All cell lines were maintained at $37^{\circ} \mathrm{C}$ and $5 \% \mathrm{CO}_{2}$.

Leukocyte binding assay: PECs were grown on 96 well plates. Approximately, $1 \times 10^{4}$ cells/well were seeded and incubated at $37^{\circ} \mathrm{C}$ for 2 days or until confluent. U937s were serum starved for 24 hours in RPMI 1640 with 1\% FBS before culture in the following groups: (1) U937s alone, and (2) U937s with MSCs (1:10 ratio) in direct contact. Adhesion molecule expression on PECs was stimulated by the addition of TNFa $(50 \mathrm{ng} / \mathrm{ml})$. Co-cultures were incubated at $37^{\circ} \mathrm{C}$ for 16 hours. U937s were stimulated with phorbol myristate acetate (PMA, 200ng/ $\mathrm{mL}$ ) for 20 minutes and then removed from co-cultures. Cells were labeled with Calcein-AM (Invitrogen, Carlsbad, CA), added to wells and allowed to adhere for one hour. Non-adherent cells were gently washed away in PBS and labeled cells that remained were quantified by fluorescent reading on the Biotek Synergy II (Biotek, Winooski, VT) at $490 \mathrm{~nm}$ wavelength excitation and $520 \mathrm{~nm}$ emission.

Flow cytometry: MSCs were characterized by flow cytometry as described previously [15]. U937s were characterized for surface adhesion markers and integrins by flow cytometry (BD Facs Calibur, BD Biosciences, San Jose, CA). U937 cells were cultured in 6 well plates for 24 hours in 2 groups: (1) U937s alone, and (2) U937s + MSCs (10:1 ratio with replicates of 4/group). The U937s were collected and subsequently treated with PMA (200ng/mL). After 20 minute incubation, the cells were collected and stained with fluorophore conjugated antibodies to CD11b, CD18, CD29, and CD62L (BD Biosciences). The cells were then analyzed on the BD LSR II flow cytometer (BD Biosciences). Expression of adhesion molecules was quantified by mean fluorescence intensity using the Flo-Jo Program software (Ashland, OR).

Nuclear NF-kappa B DNA binding activity: Nuclear extracts were prepared using the Nuclear Extract Kit from Active Motif (Carlsbad, $\mathrm{CA})$ according to the manufacturer's protocol. Protein concentration was determined by Bradford assay (Pierce Biochemicals). p50 and p65 DNA binding was quantified by Trans-AM NF-kappa B DNA binding ELISA from Active Motif (Carlsbad, CA), according to the manufacturer's protocol. Nuclear extracts $(2-5 \mu \mathrm{g})$ were combined with a standardized biotinylated oligonucleotide and plated on to a streptavidin coated plate and incubated for one hour at room temperature. The plate was then washed three times with wash buffer and antibodies to NF-kappa B p65 and p50 subunits were added and incubated for one hour. HRP conjugated secondary antibody was then added and incubated for one hour. The plate was then developed and read on a 96 well plate spectrophotometer at $450 \mathrm{~nm}$ with reference wavelength of $655 \mathrm{~nm}$.

Leukocyte NF-kappa B reporter gene assay: U937s were cotransfected with NF-kappa B cis-Reporter plasmid $\left(1 \mu \mathrm{g} / 5 \times 10^{5}\right.$ cells, Agilent Technologies, Santa Clara, CA) and CMV-Renilla luciferase plasmid (Promega Madison, WI) using the Amaxa electroporation system (Walkersville, MD), according to the manufacturer's protocol. The cells were then cultured in RPMI-1640 with 10\% FBS for 16 hours. U937s were then collected, pooled, counted and plated in 6 well plates either with or without MSCs. The cells were then incubated at $37^{\circ} \mathrm{C}$ overnight. In the morning either lipopolysaccharide (LPS, $5 \mu \mathrm{g} / \mathrm{mL}$ ) or PBS (vehicle) was added to the dish. The cells were incubated again at $37^{\circ} \mathrm{C}$ for 4 hours Figure 5. U937s were then collected, lysed and assayed according to the Promega (Madison, WI) Dual Luciferase Assay kit protocol.

Flow cytometric cytokine bead assay: U937s were cultured either alone in varying concentrations $\left(1.5 \times 10^{5} / \mathrm{mL}, 3.75 \times 10^{5} / \mathrm{mL}\right.$, and $5 \times$ $\left.10^{5}\right)$, or with MSCs in varying ratios (1:2, 1:5 and 1:10) in 6 well plates for 12 hours. LPS $(5 \mu \mathrm{g} / \mathrm{mL})$ or vehicle was then added to the plates to increase the baseline of NF-kappa B. After a four hour incubation the supernatants were collected. Cytokines (TNF, IL-1B, IL-6, IL-8, and IL10) were quantified by flow cytometry by following the manufacturer's protocol for the human inflammatory cytokines bead assay kit (BD Biosciences Cat. \#551811, Franklin Lakes, NJ).

\section{Statistical analysis}

Statistical analysis was performed using Microsoft Excel and Stata 11 (College Station, TX). Analysis was performed by Student's t-test or one-way ANOVA with post-hoc Bonferroni correction, as needed.

\section{Results}

\section{Mscs inhibit adhesion of U937s to pulmonary endothelial cells (pecs)}

Leukocyte adhesion to endothelium is a critical component in the development of an inflammatory response to injury. Injured vasculature and activated leukocytes often upregulate expression of adhesion molecules that mediate binding between the two cell types. Multiple factors are responsible for the compromise of the endothelial barrier in injury. The lungs are often one of the most sensitive organs to inflammatory insults and compromise of the alveolar-capillary barrier is found early after the initial insult whether it is trauma or infection [16]. In addition to factors such as hypoxia and thrombin, inflammatory changes caused by cytokine and chemokine release, leukocyte adhesion, diapedesis and infiltration into the lungs have all been shown to contribute to the clinical severity and outcome in ALI/ARDS [3]. Taking this into account and the demonstrated predominance of IVadministered MSCs in the pulmonary vasculature, we chose to focus our studies upon the effects of MSCs on pulmonary endothelial cells (PECs). We sought to determine if MSCs modulate leukocyte binding to PECs stimulated with the inflammatory cytokine TNFa. In these studies, U937s were co-cultured with MSCs for 24 hours followed by stimulation with PMA, to stimulate calcium dependent binding (see schematic Figure 1A). PECs were treated with TNFa $(10 \mathrm{ng} / \mathrm{ml}$ ) and binding of calcein-labeled cells to treated PECs was quantified by flourimetry Figure 1B. U937 cells are a monocytoid line that we have previously used to study leukocyte-endothelial adhesion $[17,18]$. Binding studies reveal that PMA stimulated U937-PEC binding and U937s co-cultured with MSCs demonstrate significantly decreased binding to PECs Figure 1B. Representative photographs of calceinlabelled U937s binding to PECs are depicted in Figure 1C. These results suggest that MSCs do indeed modulate leukocyte endothelial cell interactions.

\section{MSCs do not affect U937 adhesion molecule expression}

To determine if the binding differences noted were due to changes 
Citation: Letourneau PA, Menge TD, Wataha KA, Wade CE, Cox CS Jr, et al. (2011) Human Bone Marrow Derived Mesenchymal Stem Cells Regulate Leukocyte-Endothelial Interactions and Activation of Transcription Factor NF-Kappa B. J Tissue Sci Eng S3:001. doi:10.4172/2157-7552. S3-001

Page 3 of 7

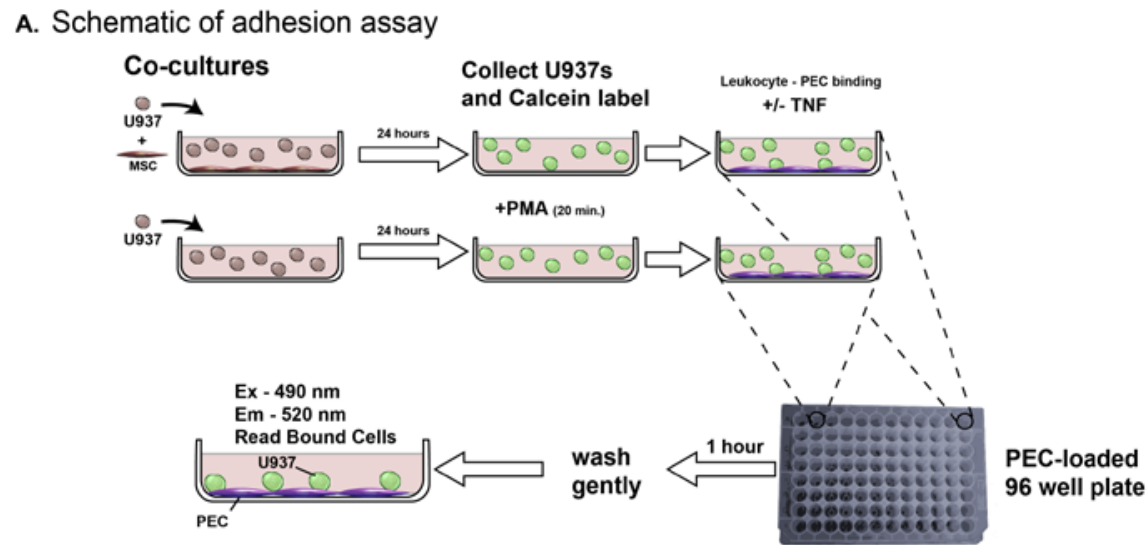

B.

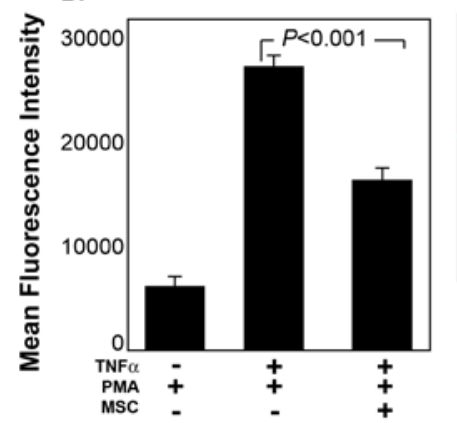

c.

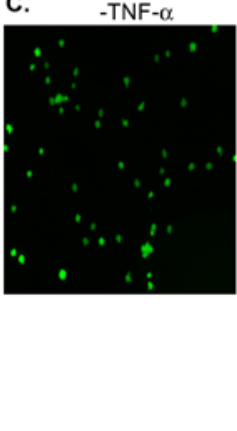

+ TNF- $\alpha$
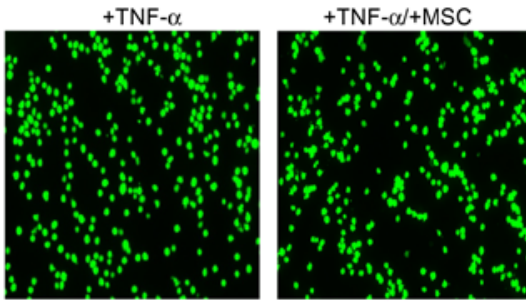

Figure 1: MSCs decrease functional leukocyte-endothelial cell binding. A. Schematic of Co-cultures: U937 leukocytes were cultured with or without MSCs for 24 hours. The cells were subsequently labeled with Calcein-AM. U937s were stimulated with PMA (200ng/mL) for 20 minutes. Pulmonary endothelial cells (PECs) were stimulated with TNF- $\alpha$ (10 ng/ml)-, 4 hours prior to addition of U937s. 25,000 U937s/well were added to a 96 well plate that was pre-loaded with confluent (PECs) The cells were incubated for 60 minutes and gently washed 3 times with PBS. Adherent cells were quantified by measured fluorescence on a BioTek Synergy 2 plate reader (Biotek, Winooski, VT). B. Binding Assay: TNF stimulation of PECs increased U937 binding (Group 1 vs. Group 2) Binding was significantly decreased in Group 2 which was co-cultured with U937s compared to Group 3. Binding was quantified by mean fluorescence intensity (MFI) on a flourimeter. C. Representative Images of Binding: Qualitative images of representative wells showing decreased binding of fluorescent U937s co-cultured with MSCs to PECs. Images were taken at 20X magnification.

in adhesion molecule expression on the surface of the U937 cells, we analyzed the expression of CD62L, CD29, CD11b and CD18. These adhesion molecules and integrins mediate binding of leukocytes to endothelial cells and the surrounding extracellular matrix. CD11b is a component of LFA-1 which binds to ICAM-1 on endothelial cells and CD18 is a component of VLA- 4 which binds to VCAM-1 on endothelial cells. In these studies, U937s were co-cultured with MSCs for 24 hours followed by stimulation with PMA for 20 minutes (See schematic in Figure 2A). Bright field microscopy in Figure $2 \mathrm{~B}$ shows culture of the U937 cells alone and Figure $2 \mathrm{C}$ shows a representative co-culture of the two cell types where the adherent MSCs are apparent in the background with adherent U937s in the foreground. Flow cytometric analysis of the U937 cells after co-culture reveals that there are no significant differences in CD62L, CD29, CD11b and CD18 expression on the U937s. Figure 2D shows no significant changes in mean fluorescent intensity $(n=4)$ for each of the representative markers. Figure 3 shows the lack of a change or shift in both groups in histogram form for each of the surface markers.

\section{MSCs inhibit NF-kappa B DNA binding}

Since we did not find any changes in leukocyte adhesion molecules with MSC treatment, we speculated that the potent differences found in leukocyte-endothelial binding may be due to an inhibition of leukocyte activation by MSCs. We chose to look at the effects of MSCs on the transcription factor NF-kappa B, a factor that has been extensively characterized in multiple disease models and has been shown to be involved in the regulation of inflammatory processes in disease [1922]. Our past work has also shown that MSCs do in fact inhibit NFkappa B in Kaposi's Sarcoma cells through modulation of the kinase Akt [15]. Using NF-kappa B activation as a surrogate readout for leukocyte activation, we found that nuclear extracts from U937s cocultured with MSCs demonstrate decreased NF-kappa B DNA binding activity determined by a DNA binding ELISA for p50 and p65 activity (see materials and methods). We found that NF-kappa B subunit p50 was significantly less active in nuclear extracts from U937s co-cultured with MSCs compared to nuclear extracts from U937s stimulated with PMA alone or U937s co-cultured with PECs as a control cell $(0.63 \pm$ 0.03 vs. $0.92 \pm 0.14$ and $0.63 \pm 0.03$ vs. $1.7 \pm 0.3$, respectively, $\mathrm{p}=0.05$ Table 1). DNA binding of the p65 subunit of NF-kappa B was also significantly inhibited in U937s cultured with MSCs versus U937s stimulated with PMA or U937s co-cultured with PECs as a control cell ( $0.34 \pm 0.06$ vs. $0.55 \pm 0.01$ and $0.34 \pm 0.06$ vs. $0.793 \pm 0.07$, respectively, $\mathrm{p}<0.05$, Table 1).

\section{MSCs inhibit NF-kappa B transcriptional activation in U937s}

Since our data suggest that MSCs inhibit activation of NF-kappa B in U937s, we sought to determine if our findings with NF-kappa B DNA binding would translate into a functional decrease in NF-kappa B mediated transcription. U937s were transfected with a reporter plasmid containing five NF-kappa B DNA binding sites upstream 
Citation: Letourneau PA, Menge TD, Wataha KA, Wade CE, Cox CS Jr, et al. (2011) Human Bone Marrow Derived Mesenchymal Stem Cells Regulate Leukocyte-Endothelial Interactions and Activation of Transcription Factor NF-Kappa B. J Tissue Sci Eng S3:001. doi:10.4172/2157-7552. S3-001

Page 4 of 7

of a firefly luciferase reporter gene. All cells were also co-transfected with a control Renilla luciferase plasmid (see schematic Figure 4A) All U937 cells were simulated with LPS to increase the baseline of NFkappa B activation. Data from the reporter gene assay showed that LPS significantly increased nuclear NF-kappa B in U937 cells cultured alone $(0.075 \pm 0.002$ vs. $0.003 \pm 0.002$, Figure 4B) U937 cells co-cultured with MSCs demonstrated decreased NF-kappa B transcriptional activation $(0.050 \pm 0.001, \mathrm{p}<0.05$ Figure $4 \mathrm{~B})$. Taken together these data do indeed suggest that MSCs inhibit NF-kappa B DNA binding and transcriptional activation, possibly providing an explanation for our noted effect of MSCs on leukocyte-endothelial interactions.

MSCs induce production of the anti-inflammatory cytokine IL-10

To better understand the mechanism of action of MSCs on the inhibition of NF-kappa B we sought to determine if MSCs modulate the expression of factors that may regulate NF-kappa B. IL-10 has been shown to be a key mediator and regulator of the anti-inflammatory effects of MSCs in multiple disease models [7]. IL-10 has also been clearly shown to regulate the activation of NF-kappa B in inflammatory cells [23]. Using a flow cytometric bead based assay, supernatants from co-cultured cells were analyzed for the production of IL-10. These studies reveal that the MSCs and unstimulated U937s do not produce detectable levels of IL-10, but when co-cultured, there is a significant increase in IL-10, $(7.5 \pm 0.53 \mathrm{pg} / \mathrm{mL}$ vs. $0 \pm 0 \mathrm{pg} / \mathrm{mL}, \mathrm{p}<0.01$, Figure 5$)$, at both 1:2 and 1:5 ratios of MSCs to U937s. Taken together these data suggest that MSCs do increase production of the anti-inflammatory cytokine IL-10, which may contribute to the noted inhibition of NFkappa B and leukocyte endothelial interactions by MSCs.

\section{Discussion}

MSCs have demonstrated benefit in preclinical and clinical models of injury and inflammation. Clinical trials in multiple inflammatory conditions, including graft versus host disease (GVHD), and Crohn's

\section{A. Schematic of adhesion molecule assay}
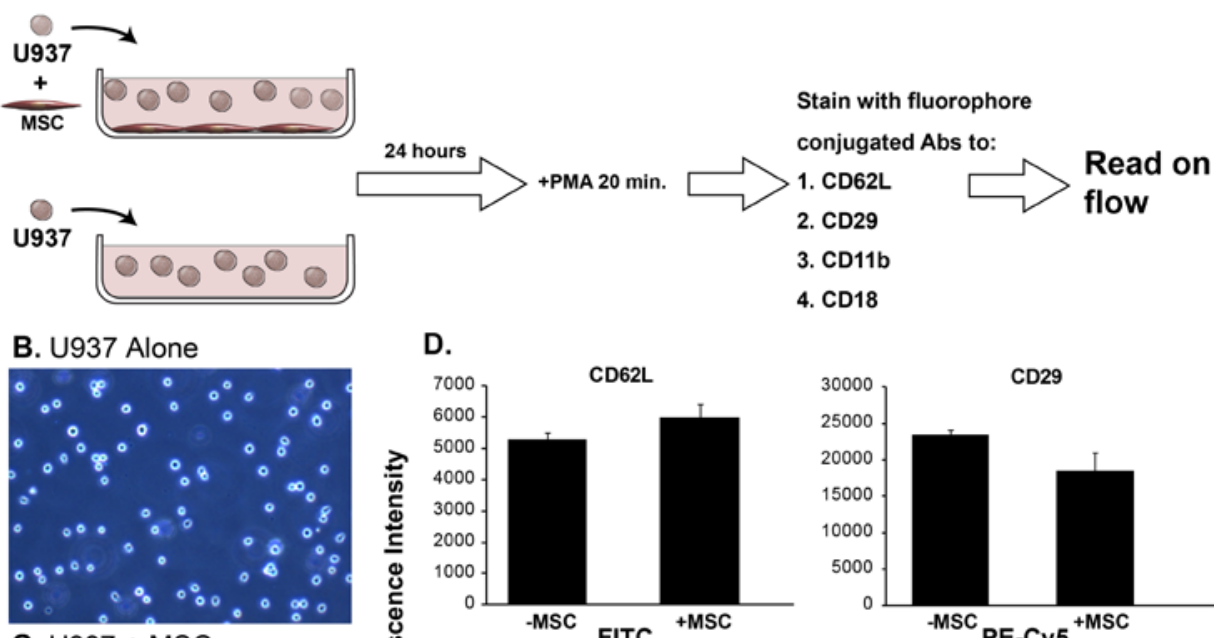

C. $\mathrm{U} 937+\mathrm{MSC}$
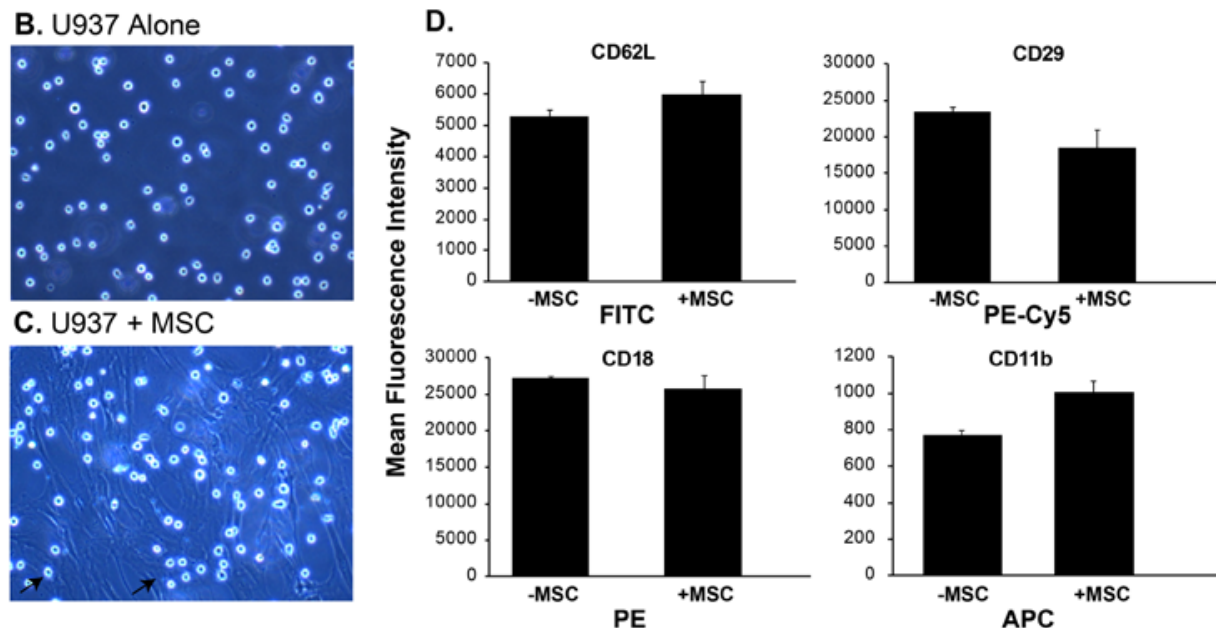

Figure 2: MSCs do not influence U937 leukocyte adhesion molecule expression. A. Schematic of adhesion molecule assay: U937 leukocytes (500,000cells/well) in 6 well plates were cultured with or without MSCs (ratio of 1:5) for 24 hours. The cells were stimulated with PMA (200ng/mL) for 20 minutes. The cells were then labeled with fluorophore conjugated antibodies to CD62L, CD29, CD11b, and CD18. B. Image U937: Representative image of U937 leukocytes alone in culture. C. Image U937 and MSC co-culture: Representative image of U937 leukocytes in co-culture with MSCs. D. Mean Flourescent Intensity changes in all markers ( $\mathrm{n}=4$ ): There were no differences in adhesion molecule expression in U937 leukocytes after co-culture with MSCs and stimulation with PMA. Adhesion molecule expression was quantified by mean fluorescence intensity for four individual culture wells.

\begin{tabular}{|l|l|l|l|l|}
\hline & Group $1(n=4)$ U937-PMA & Group 2 (n=4) U937+PMA & Group 3 (n=4) U937s+PMA+PEC & Group 4 (n=4) U937s+PMA+MSC \\
\hline NK-kB p65 & $0.419 \pm 0.03$ & $0.543 \pm 0.01$ & $0.793 \pm 0.07$ & $0.336 \pm 0.06$ \\
\hline NK-kB p50 & $0.972 \pm 0.05$ & $0.924 \pm 0.14$ & $1.76 \pm 0.28$ & $0.633 \pm 0.03$ \\
\hline
\end{tabular}

Table 1: MCSs inhibit NF-kappa B p50 and p65 DNA binding in U937s. U937 cells were cultured with or without MSCs and followed by stimulation with LPS (5ng/ml) to mobilize nuclear translocation of NF-kappa B. Nuclear extracts were prepared using the Nuclear Extract Kit from Active Motif (Carlsbad, CA). p50 and p65 DNA binding was quantified by Trans-AM NF-kappa B DNA binding ELISA from Active Motif. NF-kappa B subunit p50 was significantly less active in nuclear extracts from U937s co-cultured with MSCs compared to nuclear extracts from U937s stimulated with PMA alone or U937s co-cultured with PECs as a control cell $(0.63 \pm 0.03$ vs. $0.92 \pm 0.14$ and $0.63 \pm$ 0.03 vs. $1.7 \pm 0.3$ respectively, $p=0.05$ ). DNA binding of the p 65 subunit of NF-kappa B was also significantly inhibited in U937s cultured with MSCs versus U937s stimulated with PMA or U937s co-cultured with PECs as a control cell $(0.34 \pm 0.06$ vs. $0.55 \pm 0.01$ and $0.34 \pm 0.06$ vs. $0.793 \pm 0.07$, respectively, $p<0.05)$. 
Citation: Letourneau PA, Menge TD, Wataha KA, Wade CE, Cox CS Jr, et al. (2011) Human Bone Marrow Derived Mesenchymal Stem Cells Regulate Leukocyte-Endothelial Interactions and Activation of Transcription Factor NF-Kappa B. J Tissue Sci Eng S3:001. doi:10.4172/2157-7552. S3-001

Page 5 of 7
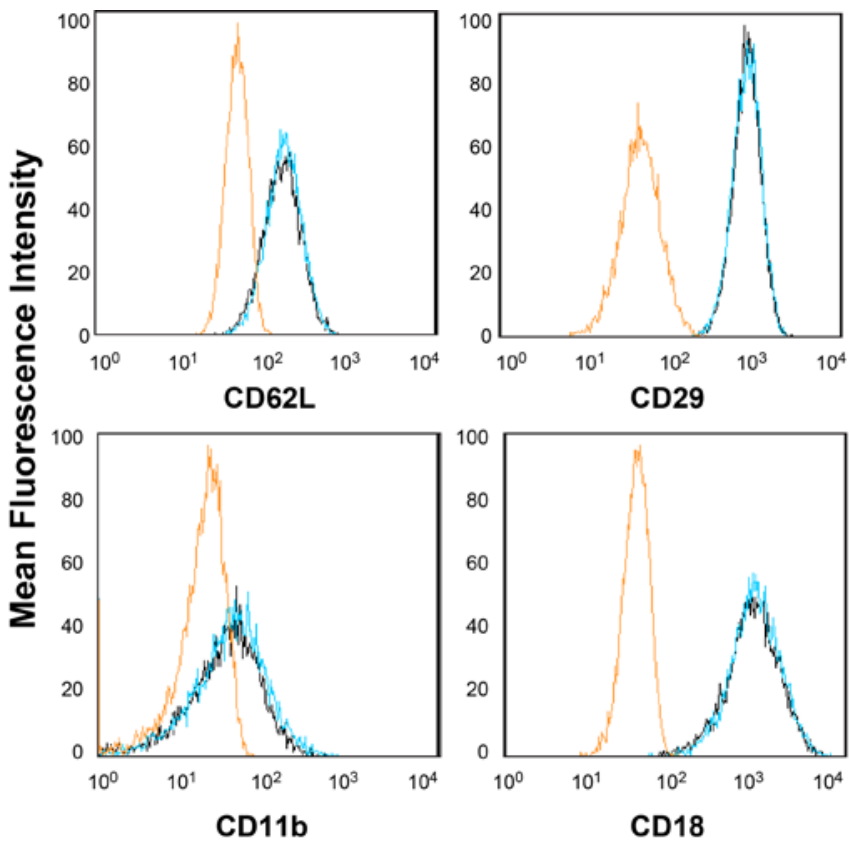

Figure 3: Flow Histograms showing that no changes are found in U937 leukocytes adhesion molecule expression. Histograms show no changes with and without MSCs in U937 adhesion molecule expression for CD62L, CD29, CD11b, and CD18. Cells were grown and stained as described in Figure 2.

colitis, have demonstrated benefit, with many trials currently still underway [24]. In preclinical models of disease, MSCs have been shown to have potent effects in many models including ALI/ARDS, arthritis, acute hepatic failure, transplant, and diabetes [6,25-29]. Nemeth et al., have shown increased survival associated with MSC therapy in sepsis [7]. While this group and other investigators have examined the immunomodulatory effects of MSCs on inflammatory cells, few have investigated the effects in relation to the vascular endothelium. The stem cell niche and the interactions between cells created by the therapeutic delivery of MSCs are still wholly unknown. In this paper we sought to better understand a defined interaction between MSCs and inflammatory cells and how this interaction affects leukocyte-endothelial cell binding. Since MSCs are often administered for therapeutic purposes intravenously, one of the main cell types they come into contact with is inflammatory cells in the pulmonary vasculature [14]. Our studies aimed to recapitulate some of these interactions in vitro, to better understand mechanistically the antiinflammatory effects of MSCs.

In this study we show that inflammatory cells (U937s) co-cultured with MSCs display diminished potential to bind to pulmonary endothelial cells. Since we did not see large differences in leukocyte adhesion markers with MSC treatment, we hypothesized that MSCs may be affecting leukocyte-endothelial adhesion through inhibitory effects on leukocyte activation. To study this further, we utilized NFkappa $\mathrm{B}$ activation as a surrogate marker for leukocyte activation. We used two methods to show that MSCs decrease NF-kappa B activity in U937s; DNA binding and transcriptional activation by NF-kappa B. Co-culture of U937s with MSCs significantly diminished both measures of NF-kappa B activity. The role of NF-kappa B on inflammation and injury has been well documented throughout the years. Investigators in Germany isolated neutrophils from severely injured trauma patients and found significantly increased levels of NF-kappa B translocation to the nucleus compared to healthy volunteers [6,30]. Similarly, researchers utilizing an animal model of trauma and sepsis found increases in NF-kappa B activation in macrophages compared to sham. By inhibiting NF-kappa B, the authors were able to demonstrate decreased activation of alveolar macrophages and increased therapeutic benefit [20]. These data as a whole suggest an important role for NFkappa B in inflammatory disease outcome. It is of interest to note that regardless of changes in leukocyte adhesion markers, there are changes in MSC treated U937 that diminish binding. This data suggests that non-specific changes U937 may be taking place that alter adhesion such as changes in conformation or matrix interactions. Further study in this area is warranted.

To determine if IL-10 may play a role in the effects of MSCs on NF-kappa B, we investigated if IL-10 production was increased in our co-cultures. We indeed found that IL-10 was significantly increased in U937s by co-culture with MSCs suggesting a possible paracrine mechanism of action for the inhibition of NF-Kappa B in leukocytes by MSCs. Interestingly, the influence of MSCs on IL-10 production has been well documented in many models in vitro and in vivo and has been suggested by multiple groups to be a key source of the therapeutic

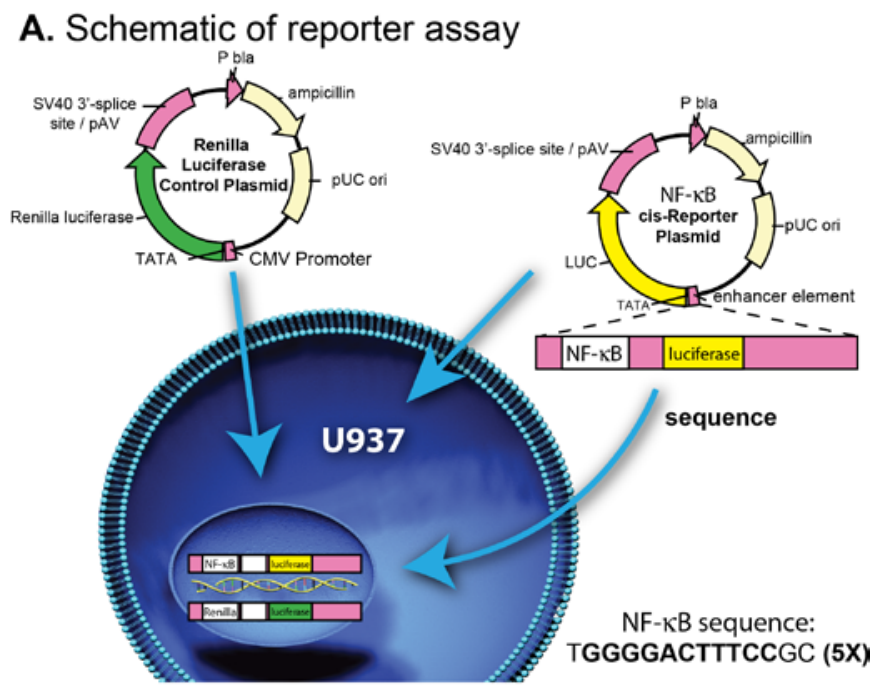

B. MSCs decrease NF- $\mathrm{KB}$ reporter activity in U937

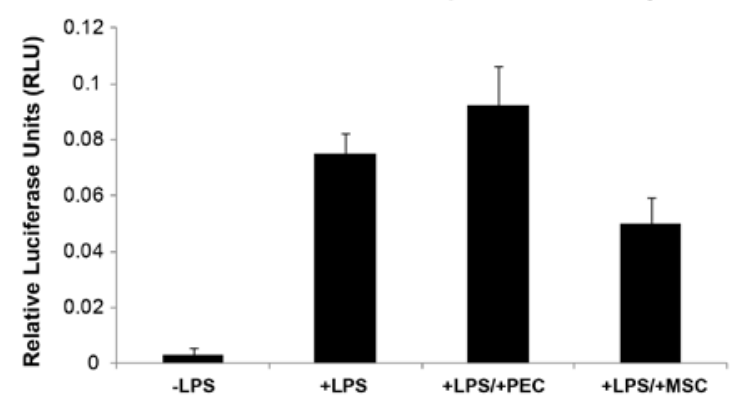

Figure 4: MSCs inhibit transcriptional activity of NF-kappa B. A. Schematic of Reporter Assay: U937 cells were transfected with NF-kappa B luciferase plasmid and Renilla firefly luciferase and subsequently cultured with and without MSCs for 24 hours. The cells then received LPS $(5 \mathrm{ng} / \mathrm{mL})$ or PBS (vehicle), and after a four hour incubation, they were collected and NF-kappa B transcription activity was quantified by the Promega Dual Luciferase Assay according to the manufacturer's protocol (Promega, Madison, WI). B. Reporter Assay: Coculture with MSCs significantly decreased NF-kappa B transcriptional activity compared to the group cultured without MSCs $(p<0.05)$. 
Citation: Letourneau PA, Menge TD, Wataha KA, Wade CE, Cox CS Jr, et al. (2011) Human Bone Marrow Derived Mesenchymal Stem Cells Regulate Leukocyte-Endothelial Interactions and Activation of Transcription Factor NF-Kappa B. J Tissue Sci Eng S3:001. doi:10.4172/2157-7552. S3-001

Page 6 of 7

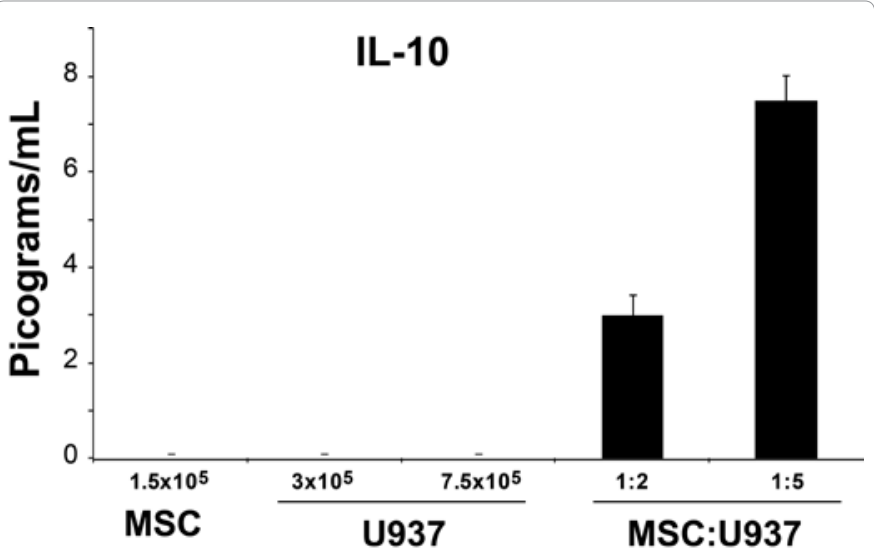

Figure 5: MSCs increase IL-10 production in U937-MSC co-culture. Supernatants collected from MSC culture $(150,000$ cells/well) alone, and U937 culture $\left(3 \times 10^{5} /\right.$ well and $7.5 \times 10^{5} /$ well $)$ alone did not contain any IL-10, as quantified by cytokine bead assay for flow cytometry (BD Biosciences, San Jose, CA). Both co-culture groups (in ratios 1:2 and 1:5, MSCs:U937s) significantly increased IL-10 production in response to stimulation with LPS $(5 \mathrm{ng} / \mathrm{mL})$.

benefit of MSCs [3,6,7,31]. A number of studies have also shown that MSCs function through soluble factors that produce a local paracrine and systemic effect [32-35]. There are many candidate factors that have been proposed as being critical to the therapeutic effects of MSCs. Our data in traumatic brain injury (TBI) support this view and have shown that intravenously delivered MSCs potently inhibit blood brain barrier permeability, without many cells present in the injured brain, suggesting the presence of soluble factors. These data and the data of others support the view that MSCs modulate inflammation and vascular stability through systemic, rather than local effects $[14,36]$. Previous work by our group has demonstrated that MSCs stabilize the endothelium and prevent disruption of the blood brain barrier through regulation of endothelial cadherin/beta-catenin signaling [5]. This effect combined with our data demonstrates a robust influence by MSCs on both the endothelium and the inflammatory response of blood leukocytes to decrease inflammatory capacity. Considering the multiple cell types involved in these interactions, the endothelial side of the "picture" is of great interest as well. Studies are currently underway to investigate the effects that MSCs have on endothelial cells and how this interaction affects leukocyte-endothelial cell interactions. Initial unpublished data from our group suggests that PECs treated with MSCs do decrease endothelial adhesion molecule expression and leukocyte binding.

In summary, we have shown that MSCs decrease leukocyteendothelial binding and NF-kappa B activation in inflammatory cells. Our data indicates that MSCs decrease leukocyte activation in response to stimulus which may be the explanation for the diminished binding to PECs. Decreases in NF-kappa B activity may be due to increased IL-10 production by monocytes and macrophages, resulting an overall decrease in the inflammatory state. MSCs remain an important area for translational study in treating the immunological response to injury, sepsis, and other inflammatory conditions.

\section{Acknowledgements}

The authors would like to thank Angela Beeler for her editorial support. The authors would also like to thank Scott Holmes for his help and expertise in graphics.

\section{Funding and Support}

This work was supported by funding from Mission Connect TIRR Foundation Houston, Texas and the National Institute of Health, T32GM008792-10.

\section{References}

1. Harting MT, Jimenez F, Xue H, Fischer UM, Baumgartner J, et al. (2009) Intravenous mesenchymal stem cell therapy for traumatic brain injury. Neurosurg 110: 1189-1197.

2. Loffredo FS, Steinhauser ML, Gannon J, Lee RT (2011) Bone marrow-derived cell therapy stimulates endogenous cardiomyocyte progenitors and promotes cardiac repair. Cell Stem Cell 8: 389-398.

3. Matthay MA, Goolaerts A, Howard JP, Lee JW (2010) Mesenchymal stem cells for acute lung injury: preclinical evidence. Crit Care Med 38: S569-573.

4. Mei SH, Haitsma JJ, Dos Santos CC, Deng Y, Lai PF, et al. (2010) Mesenchymal stem cells reduce inflammation while enhancing bacterial clearance and improving survival in sepsis. Am J Respir Crit Care Med 182: 1047-1057.

5. Pati S, Khakoo AY, Zhao J, Jimenez F, Gerber MH, et al. (2011) Human mesenchymal stem cells inhibit vascular permeability by modulating vascular endothelial cadherin/beta-catenin signaling. Stem Cells Dev 20: 89-101.

6. Gupta N, Su X, Popov B, Lee JW, Serikov V, et al. (2007) Intrapulmonary delivery of bone marrow-derived mesenchymal stem cells improves survival and attenuates endotoxin-induced acute lung injury in mice. J Immunol 179 : 1855-1863.

7. Nemeth K, Leelahavanichkul A, Yuen PS, Mayer B, Parmelee A, et al. (2009) Bone marrow stromal cells attenuate sepsis via prostaglandin $\mathrm{E}(2)$-dependent reprogramming of host macrophages to increase their interleukin-10 production. Nat Med 15: 42-49.

8. Sueblinvong V, Weiss DJ (2009) Cell therapy approaches for lung diseases: current status. Curr Opin Pharmacol 9: 268-273.

9. Ren G, Roberts Al, Shi Y (2011) Adhesion molecules: key players in Mesenchymal stem cell-mediated immunosuppression. Cell Adh Migr 5: 20-22.

10. Bartholomew A, Sturgeon C, Siatskas M, Ferrer K, McIntosh K, et al. (2002) Mesenchymal stem cells suppress lymphocyte proliferation in vitro and prolong skin graft survival in vivo. Exp Hematol 30: 42-48.

11. Keyser KA, Beagles KE, Kiem HP (2007) Comparison of mesenchymal stem cells from different tissues to suppress T-cell activation. Cell Transplant 16 $555-562$.

12. Le Blanc K, Tammik L, Sundberg B, Haynesworth SE, Ringden O (2003) Mesenchymal stem cells inhibit and stimulate mixed lymphocyte cultures and mitogenic responses independently of the major histocompatibility complex. Scand J Immunol 57: 11-20.

13. Tyndall A, Walker UA, Cope A, Dazzi F, De Bari C, et al. (2007) Immunomodulatory properties of mesenchymal stem cells: a review based on an interdisciplinary meeting held at the Kennedy Institute of Rheumatology Division, London, UK, 31 October 2005. Arthritis Res Ther 9: 301

14. Fischer UM, Harting MT, Jimenez F, Monzon-Posadas WO, Xue H, et al. (2009) Pulmonary passage is a major obstacle for intravenous stem cell delivery: the pulmonary first-pass effect. Stem Cells Dev 18: 683-692.

15. Khakoo AY, Pati S, Anderson SA, Reid W, Elshal MF, et al. (2006) Human mesenchymal stem cells exert potent antitumorigenic effects in a model of Kaposi's sarcoma. J Exp Med 203: 1235-1247.

16. Ware LB, Matthay MA (2000) The acute respiratory distress syndrome. N Eng J Med 342: 1334-1349

17. Pati S, Cavrois M, Guo HG, Foulke JS Jr, Kim J, et al. (2001) Activation of NFkappaB by the human herpesvirus 8 chemokine receptor ORF74: evidence for a paracrine model of Kaposi's sarcoma pathogenesis. J Virol 75: 8660-8673.

18. Pati S, Pelser CB, Dufraine J, Bryant JL, Reitz MS Jr, et al. (2002) Antitumorigenic effects of HIV protease inhibitor ritonavir: inhibition of Kaposi sarcoma. Blood 99: 3771-3779.

19. Damle SS, Moore EE, Nydam TL, Banerjee M, Gamboni-Robertson F, et al. (2007) Postshock mesenteric lymph induces endothelial NF-kappaB activation. J Surg Res 143: 136-140.

20. Jarrar D, Kuebler JF, Rue LW, 3rd, Matalon S, Wang P, et al. (2002) Alveolar macrophage activation after trauma-hemorrhage and sepsis is dependent on NF-kappaB and MAPK/ERK mechanisms. Am J Physiol Lung Cell Mol Physiol 283: L799-805

21. Spehlmann ME, Eckmann L (2009) Nuclear factor-kappa B in intestina protection and destruction. Curr Opin Gastroenterol 25: 92-99. 
Citation: Letourneau PA, Menge TD, Wataha KA, Wade CE, Cox CS Jr, et al. (2011) Human Bone Marrow Derived Mesenchymal Stem Cells Regulate Leukocyte-Endothelial Interactions and Activation of Transcription Factor NF-Kappa B. J Tissue Sci Eng S3:001. doi:10.4172/2157-7552. S3-001

22. Zmijewski JW, Lorne E, Zhao X, Tsuruta Y, Sha Y, et al. (2009) Antiinflammatory effects of hydrogen peroxide in neutrophil activation and acute lung injury. Am J Respir Crit Care Med 179: 694-704.

23. Smallie T, Ricchetti G, Horwood NJ, Feldmann M, Clark AR, et al. (2010) IL-10 inhibits transcription elongation of the human TNF gene in primary macrophages. J Exp Med 207: 2081-2088.

24. Abdi R, Fiorina P, Adra CN, Atkinson M, Sayegh MH (2008) Immunomodulation by mesenchymal stem cells: a potential therapeutic strategy for type 1 diabetes. Diabetes 57: 1759-1767.

25. Augello A, Tasso R, Negrini SM, Cancedda R, Pennesi G (2007) Cell therapy using allogeneic bone marrow mesenchymal stem cells prevents tissue damage in collagen-induced arthritis. Arthritis Rheum 56: 1175-1186.

26. Ortiz LA, Dutreil M, Fattman C, Pandey AC, Torres G, et al. (2007) Interleukin 1 receptor antagonist mediates the antiinflammatory and antifibrotic effect of mesenchymal stem cells during lung injury. Proc Natl Acad Sci USA 104: $11002-11007$

27. Parekkadan B, van Poll D, Suganuma K, Carter EA, Berthiaume F, et al. (2007) Mesenchymal stem cell-derived molecules reverse fulminant hepatic failure. PLoS One 2: e941.

28. Di Nicola M, Carlo-Stella C, Magni M, Milanesi M, Longoni PD, et al. (2002) Human bone marrow stromal cells suppress T-lymphocyte proliferation induced by cellular or nonspecific mitogenic stimuli. Blood 99: 3838-3843.

29. Zhang W, Qin C, Zhou ZM (2007) Mesenchymal stem cells modulate immune responses combined with cyclosporine in a rat renal transplantation model. Transplant Proc 39: 3404-3408.
30. Stegmaier JC, Kirchhoff C, Bogner V, Matz M, Kanz KG, et al. (2008) Dynamics of neutrophilic NF-kB translocation in relation to IL-8 mRNA expression after major trauma. Inflamm Res 57: 547-554.

31. Maggini J, Mirkin G, Bognanni I, Holmberg J, Piazzon IM, et al. (2010) Mouse bone marrow-derived mesenchymal stromal cells turn activated macrophages into a regulatory-like profile. PLoS One 5: e9252.

32. Gnecchi M, He H, Noiseux N, Liang OD, Zhang L, et al. (2006) Evidence supporting paracrine hypothesis for Akt-modified mesenchymal stem cellmediated cardiac protection and functional improvement. Faseb J 20: 661-669.

33. Lee RH, Pulin AA, Seo MJ, Kota DJ, Ylostalo J, et al. (2009) Intravenous hMSCs improve myocardial infarction in mice because cells embolized in lung are activated to secrete the anti-inflammatory protein TSG-6. Cell Stem Cell 5: 54-63.

34. Qu C, Mahmood A, Lu D, Goussev A, Xiong Y, et al. (2008) Treatment of traumatic brain injury in mice with marrow stromal cells. Brain Res 1208: 234239.

35. Lee RH, Seo MJ, Reger RL, Spees JL, Pulin AA, et al. (2006) Multipotent stromal cells from human marrow home to and promote repair of pancreatic islets and renal glomeruli in diabetic NOD/scid mice. Proc Natl Acad Sci USA 103: $17438-17443$

36. Walker PA, Shah SK, Jimenez F, Gerber MH, Xue H, et al. (2010) Intravenous multipotent adult progenitor cell therapy for traumatic brain injury: preserving the blood brain barrier via an interaction with splenocytes. Exp Neurol 225 341-352. 